\title{
THE EFFERENT PATHWAY OF EPILEPTIC SEIZURES FOR THE FACE FOLLOWING CORTICAL STIMULATION DIFFERS FROM THAT FOR LIMBS
}

\author{
TAKASHI HAYASHI* \\ Department of Physiology, School of Medicine, Keio University
}

From experiments on monkeys and dogs, in which a chemical stimulation was applied to the cortical or the subcortical motor nuclei, the author established the levels and paths for clonic convulsion in the central nervous system in higher animals (2) as shown in fig. 1.

The author's method of chemical stimulation consisted of injecting a very minute quantity $(0.005-0.01 \mathrm{cc}$.) of certain chemical substances by means of a small metal capillary tube inserted into the grey matter, and producing certain types of movements, among which were clonic convulsions, when solutions of picrotoxine, nicotine, pentamethylenterazol and sodium glutamate were used. Effects were obtained from the grey matter only, and if the substances were given in any white matter, no motor effects occurred. Accordingly if the method was combined with removal of each of the subcortical nuclei, the nuclear levels could be confirmed only where there were relay stations of each type of motor neurone.

Fig. 1 shows that there are five levels which elicit clonic convulsions (abbreviated as $\mathrm{KK}$ ), focal or generalized, in monkeys as well as in dogs. Among them, the neurones of the four levels (cerebrum, thalamus, nucleus lenticularis, cerebellum) converge into the globus pallidus of both sides, so that a

FIG. 1. Levels which elicit clonic con. vulsion and its pathways in the central nervous system of monkeys as well as of man. (2)

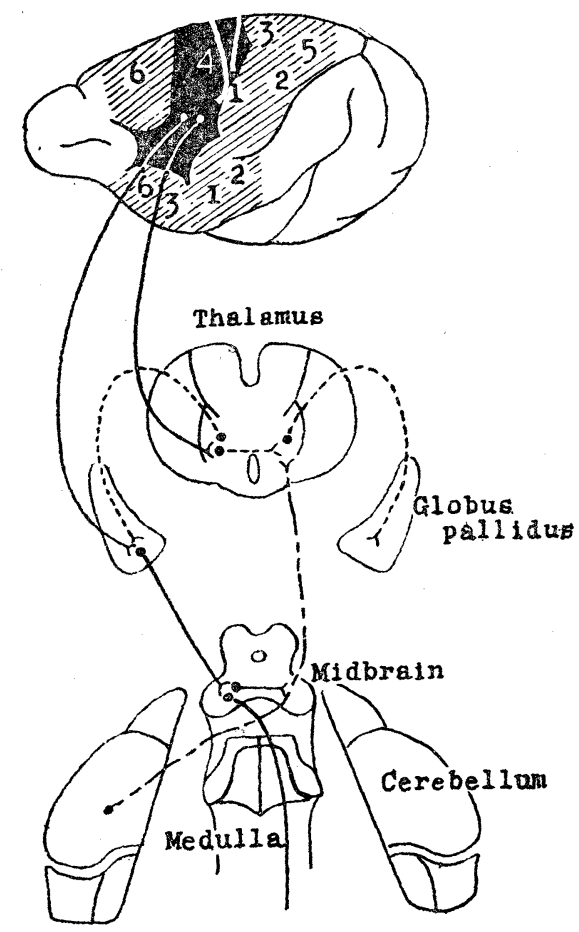

Received for publication April 28, 1953.

* 林 高喿 
convulsion can not be produced from the above four levels, when the lower boundary of the globus pallidus is severed. The scheme in fig. 1 would be applicable also to human beings, for lenticotomy in epileptic patients cured the disease in several examples.

There are two types of generalized epileptic seizures, one is the clonic convulsion which begins in the face, trunk, limbs, and tail at the same time, the other is the focal type which begins from any part of the face or limbs and involves the whole body. The author found that this focal type should be subdivided, one the convulsion which begins in the face muscles and the other which begins from a limb or trunk, and he has reported the latter. These two were different from each other in their efferent pathways.

In monkeys, the motor area in the cortex has long been established as in fig. 2, which is Vogts' diagram of the principal cytoarchitectural areas in monkey brain (4), in which Area $4 a$ is the leg area, $4 b$, the arm area and $4 c$, the face area. When an electrical stimulation is applied to $4 a$, if the duration and strength of faradization is short and weak, muscles of the opposite side of the face cerresponding to the site of the stimulated cortex will contract, for example, a movement of the eyelid, cheek, nostril, lip, tongue or swallowing and mastication. If the stimulation is longer in duration and stronger, a clonic convulsion sets in suddenly in the focal type or generalized one.

Movements of the eyes and ears do not appear from stimulation of area $4 c$ but from the other special areas in the frontal or occipital lobes in monkeys as well as in dogs.* When the stimulation was shorter, the eye movement was a conjugate deviation to the opposite side, which was sustained during stimulation, but when it was longer and stronger, the deviation continued several seconds after the cessation of stimulation, or it would shift to a nystagmus and continue. At present, the author calls continuation of movements after cessation of stimula-

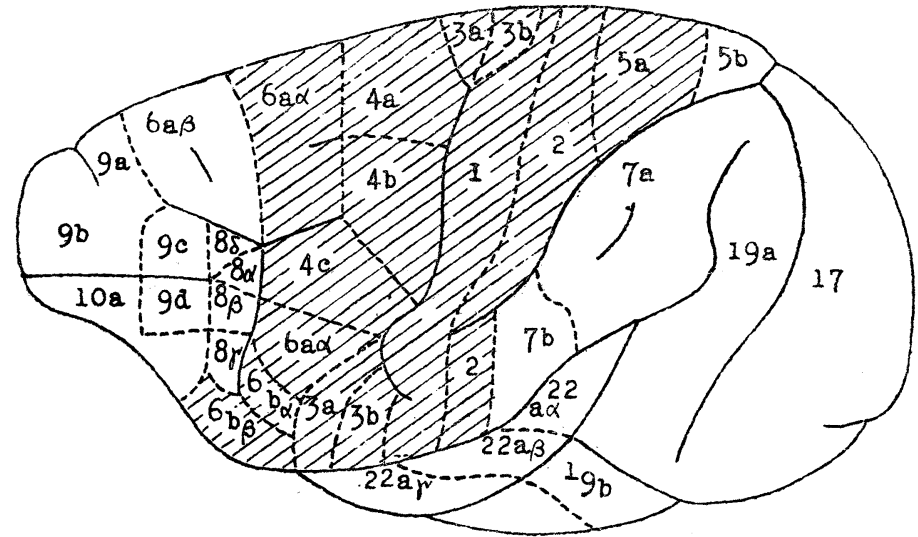

FIG. 2. Vogts' diagram of cytoarchitectural areas of the monkey (redrawn and shaded by the author).

* In dogs, the frontal eye field was found by the author as shown in Table 13 but the frontal ear field was obscure in its boundary between the other fields, which will be discussed in a later section. 
tion or nystagmus, clonic eye seizures. If so, the same is true about ear movement. When the occipital ear field is stimulated electrically, the contralateral ear retracts first, but a longer and stronger stimulation produces a fluttering movement of the ears, similar to that of the bird's wings which the author calls temporarily clonic ear seizures.

As was shown in fig. 1, generalized epileptic seizures were produced by stimulation of the shaded area, but after the motor areas (Area $4 a, 4 b, 4 c$ ) were extirpated totally, stimulation outside of these areas could not produce any more seizures, so that the author called them the extramotor area (2). In this sense, the eye or ear field was not the extramotor area to the Area 4, for the seizures could not be generalized from these fields to the face area as shown in table 1. Accordingly the author studied first only the seizures from the face area of apes as well as dogs looking experimentally for the course of its efferent pathway.

TABLE 1. Areas from Which Focal Seizures of Face Muscles Were Produced in Monkeys (See also table 12.)

\begin{tabular}{c|c|c|c}
\hline $\begin{array}{c}\text { Area } \\
\text { stimulated }\end{array}$ & $\begin{array}{c}\text { Seizures } \\
\text { first produced } \\
\text { (Area 4a) }\end{array}$ & $\begin{array}{c}\text { Generalization } \\
\text { to face }\end{array}$ & $\begin{array}{c}\text { Generalization } \\
\text { to limbs }\end{array}$ \\
\hline $\begin{array}{c}\text { contralateral face } \\
\text { muscles } \\
\text { contralateral eyelid }\end{array}$ & $\begin{array}{c}\text { bilateral face } \\
\text { muscles } \\
\text { bilateral eyelids } \\
\text { bilateral ears }\end{array}$ & four limbs \\
$\begin{array}{c}\text { Frontal eye field } \\
\text { (Area 8, 9) }\end{array}$ & $\begin{array}{c}\text { contralateral devi- } \\
\text { ation of eyes } \\
\text { adversive move- } \\
\text { ments of neck } \\
\text { seizures of eyelids } \\
\text { seizures of ears }\end{array}$ & -* \\
\hline $\begin{array}{c}\text { Occipital eye field } \\
\text { Area 19a) }\end{array}$ & $\begin{array}{c}\text { contralateral devi- } \\
\text { ation of eyes }\end{array}$ & - & - \\
\hline Occipital ear field & $\begin{array}{c}\text { fluttering of the } \\
\text { contralateral ear }\end{array}$ & $\begin{array}{c}\text { fiuttering of } \\
\text { bilateral ears }\end{array}$ & four limbs \\
\hline Limbs area & contralateral limb \\
or limbs & $\begin{array}{l}\text { bilateral face } \\
\text { muscles } \\
\text { bilateral eyelids } \\
\text { bilateral ears }\end{array}$ & - \\
\hline
\end{tabular}

* If electric stimulation covered the neighbouring areas, a clonic convulsion was produced in the face muscles, then generalised to the limb muscles.

\section{EXPERIMENTS ON MONKEYS}

\section{The focal seizures from the face area did spread to the whole body}

When an electrical or chemical stimulation was applied to Area $4 a$, the seizure began in the leg and spread to all limbs and the face, conversely also stimulation to $4 c$ elicited seizures from a part of the face and spread to all limbs, as shown in table 2. 
TABLE 2. From Area $4 c$, the Seizures Began in the Face and Spread to the Whole Body

\begin{tabular}{|c|c|}
\hline Experiment No. 1 & monkey female $3.5 \mathrm{~kg}$. \\
\hline $\begin{array}{r}3 \mathrm{hr} .10 \mathrm{~min} . \\
0 \text { sec. } \\
3 \\
7 \\
10 \\
25\end{array}$ & $\begin{array}{l}\text { Left cortex } 4 c \text { was stimulated electrically (duration } 5 \text { secs.). } \\
\text { Clonic seizures began in lips, nostrils, eyelids and ears. } \\
\text { Seizures spread to right fore and hind limbs. } \\
\text { It was generalized to the left fore and hind limbs. } \\
\text { The generalized epileptic seizure continued for } 15 \text { secs. and } \\
\text { stopped at the same time. }\end{array}$ \\
\hline Experiment No. 2 & monkey female $4.5 \mathrm{~kg}$. \\
\hline $\begin{array}{cr}1 \text { hr. } 20 \text { min. } 0 \text { sec. } \\
22 & 15 \\
23 & 0 \\
24 & 35 \\
& 50 \\
& 52 \\
26 & 0\end{array}$ & $\begin{array}{l}\text { Nicotinization was applied at the left Area } 4 c \text {. } \\
\text { A clonic convulsion started in the right cheek and lip. } \\
\text { A convulsion of the right neck and shoulder was added. } \\
\text { A convulsion of the left neck and shoulder was added. } \\
\text { Now, it spread to both face muscles, lips, nostrils, eyelids and ears.* } \\
\text { It spread to the right fore limb and then to all limbs. } \\
\text { The convulsion all over the body ceased at the same time. }\end{array}$ \\
\hline
\end{tabular}

* The secretion of saliva was observed, but not described. (See table 15.)

2. After extirpation of the homolateral leg and arm area, stimulation to the face area produced seizures, in the contralateral face only

If spread of the seizures to the whole body depends upon the radiation of the central nervous mechanism within the cortex, when the homolateral limb area is extirpated, the seizure following the stimulation to the face area can not spread to limbs. But if the radiation would occur subcortically, there should be some other rule about the spreading of seizures. The experimental results

TABLE 3. Elimination of a Part of the Cortex and Types of Seizure (monkeys and dogs)

\begin{tabular}{|c|c|c|}
\hline $\begin{array}{l}\text { Site of } \\
\text { stimulation }\end{array}$ & $\begin{array}{l}\text { Eliminated } \\
\text { area or part }\end{array}$ & Types of seizure \\
\hline 1 Area $4 c$ & Homolateral $4 a, 4 b$ & $\mathrm{KK}$ in the contralateral face only \\
\hline 2 Area $4 a, 4 b$ & Homolateral $4 c$ & Generalized seizure except in the contralateral face \\
\hline 3 Area $4 c$ & Contralateral $4 c$ & Generalized seizure except in the homolateral face \\
\hline 4 Area $4 a, 4 b$ & Contralateral $4 c$ & Generalized seizure except in the homolateral face \\
\hline 5 Face area* & $\begin{array}{l}\text { Homolateral limb } \\
\text { area }\end{array}$ & $\mathrm{KK}$ in the contralateral face only \\
\hline 6 Limb area & $\begin{array}{l}\text { Contralateral face } \\
\text { area }\end{array}$ & $\begin{array}{l}\text { Generalized seizure except in the contralateral } \\
\text { face }\end{array}$ \\
\hline 7 Face area & $\begin{array}{l}\text { Contralateral } \\
\text { hemisphere }\end{array}$ & $\begin{array}{l}\text { Generalized seizure except in the homolateral } \\
\text { face }\end{array}$ \\
\hline 8 Face area & $\begin{array}{l}\text { Contralateral face } \\
\text { area }\end{array}$ & $\begin{array}{l}\text { Generalized seizure except in the homolateral } \\
\text { face }\end{array}$ \\
\hline
\end{tabular}

* In dogs, as shown in fig. 3, the face area covered Gyri coronarius, ectosylvius, compositus anterior (shaded) and the limb area is labelled as gyrus sigmoideus. 
from this problem were rather beyond our expectation, as shown in table 3-(1). Not only did radiation fail to occur in the limb area, but the seizure occured in the contralateral face muscles only.

These results showed that the motor cells for clonic covulsion of the face area innervated only the contralateral face muscles. If so, when the face area of one hemisphere was extirpated, stimulation of the other hemisphere must elicit generalized seizures with the exception of those of the homolateral face muscles. This inference was confirmed in the experiments of table 3-(3).

3. After the face area was extirpated, stimulation to the limb area produced seizures in all limbs, trunk, tail and in the homolateral face muscles

It was confirmed from the above experiments, that the radiation of the motor mechanism for clonic convulsions from the face area went to the limb area of the homolateral cortex. Then, how would the radiation from the limb area to the face area occur? Table 3-(2), showed that, when the homolateral face area was removed, stimulation to the limb area produced a seizure in four limbs and it spread to the homolateral face muscle. In this case, since the motor mechanism of the clonic convulsion could not radiate from the limb area to the absent face area of the homolateral cortex, then it must spread via some subcortical mechanism. Then the author performed an experiment in which a stimulation was applied to Area 4 of one hemisphere and examined the radiation of the epileptic seizure having produced a longitudinal lesion between the hemispheres down the fissure from above the cerebrum to the lower limit of the

TABLE 4. Results Obtained When a Longitudinal Cut Was Made between the Hemispheres Down to the Lower Limit of the Diencephalon

\begin{tabular}{|c|c|c|c|}
\hline \multicolumn{3}{|c|}{ Experiment No. 7} & monkey female $4 \mathrm{~kg}$. \\
\hline $1 \mathrm{hr}$. & $40 \mathrm{~min}$. & 0 sec. & Trepanated. \\
\hline 3 & & 0 & The left $4 b$ was electrically stimulated. (duration 3 secs.) \\
\hline & & 6 & $\begin{array}{l}\text { A seizure was produced in the right limbs and spread to the } \\
\text { left limbs and the bilateral face muscles. }\end{array}$ \\
\hline & & 17 & The seizures stopped all over the body at the same time. \\
\hline & 45 & 0 & $\begin{array}{l}\text { A longitudinal cut was made between both hemispheres to the } \\
\text { lower limit of the corpus callosum. }\end{array}$ \\
\hline & 46 & 0 & The left $4 b$ was electrically stimulated. (duration 5 secs.) \\
\hline & & 6 & $\begin{array}{l}\text { KK began in the right fore limbs and spread to both sides of } \\
\text { the face. }\end{array}$ \\
\hline & & 10 & It spread to the left fore limb. \\
\hline & & 15 & KK stopped at the same time. \\
\hline & 48 & 0 & $\begin{array}{l}\text { A longitudinal cut was made, further down to the lower boundary } \\
\text { of the thalamus. }\end{array}$ \\
\hline & 50 & 0 & The left $4 b$ was electrically stimulated. \\
\hline & & 6 & $\begin{array}{l}\text { The seizure was produced in the right lip, nostril and other face } \\
\text { muscles and fore limbs of both sides. }\end{array}$ \\
\hline & & 17 & $\begin{array}{l}\text { KK of the face did not generalize to the left side and ended } \\
\text { at the same time. }\end{array}$ \\
\hline & 51 & 30 & No more convulsion. \\
\hline
\end{tabular}


thalamus as shown in table 4. Stimulation of Area 4 produced seizures in all limbs and both sides of the face, when the hemispheres were separated by severing the corpus callosum. But in the preparation in which the hemispheres were separated with a severed thalamus, a seizure occurred in the homolateral face muscles and four limbs. It was the same result as in table 5 , and it showed that the questionable radiation for face seizures occurred through the thalamus, from the stimulated hemisphere to the face area of the other side. Of course radiation from the limb area of a hemisphere in order to produce seizures of all limbs occurred through the subcortical mechanism i.e., through the connection between each side in the thalamus as well as in the midbrain as shown in fig. 1.

Thus the radiation mechanism of spread of the seizures from the limb area to the face area did not need the radiation between the hemispheres, but that of the connection between the thalamus of both sides. These relations between both hemispheres for the face seizures could be schematised as in fig. 4 .

\section{EXPERIMENTS ON DOGS}

\section{The relation between the face and limb areas in the cortical seizures for the face}

If the relation between the face and limb area in epileptic seizures following cortical stimulation in monkeys can be seen as such also in dogs, further studies on the problem, especially on the efferent pathway from the cerebrum, can be more easily done in dogs. Experiments on monkeys were very expensive, in our laboratory, even before the war, and now they are more expensive.

The cortical face areas of dogs have been studied by several authors and the area from which epileptic seizures for the face began, was reported recently by the author (3) as in fig. 3 .

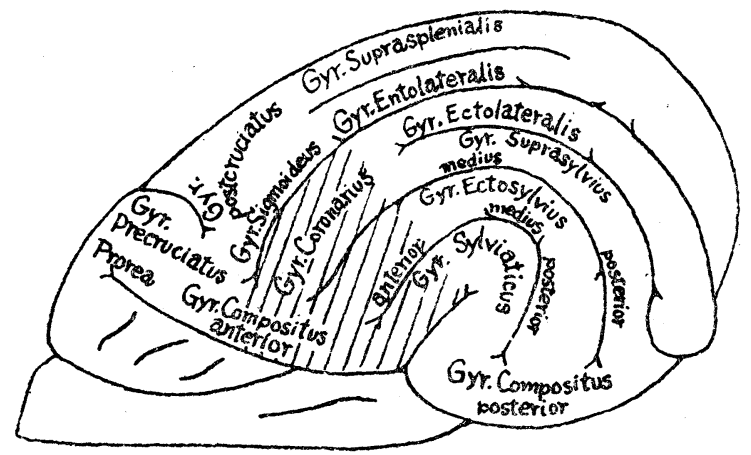

FIG. 3. The names of the gyri of the outer surface of the left hemisphere of dogs.

The shaded area in fig. 3 is the face area of dogs which corresponds to the Area $4 c$ of apes, through which seizures of face muscles will appear from the extramotor area. Of course from these areas, a generalized seizure in the focal type will be produced as shown in the following experiments.

Stimulation of the face area produced clonic convulsions which began in the contralateral face muscles and spread to the whole body as in table 5 in a dog. 
(See also table 2.) After the limb motor area was totally extirpated, stimulation of the face area could not generalize to all limbs, as in table 3-(5).

Now, the shaded area was totally extirpated and the limb area was stimulated, the results were as in table 3-(6), it was quite the same as in table 3-(4) of monkeys.

TABLE 5. Seizures Following Stimulation in the Gyrus Ectosylvius Ant. Were Spread to the Whole Body

\begin{tabular}{|c|c|c|c|}
\hline \multicolumn{3}{|c|}{ Experiment No. 1} & Dog male $12 \mathrm{~kg}$. \\
\hline \multirow[t]{11}{*}{$6 \mathrm{hr}$. } & $10 \mathrm{~min}$ & 0 sec. & $\begin{array}{l}\text { The left anterior ectosylvian gyrus was stimulated electrically. } \\
\text { (duration of the faradization was } 5 \text { secs.) }\end{array}$ \\
\hline & & 3 & Clonic convulsion began in the right side of the face. \\
\hline & & 4 & It spread to the left face.* \\
\hline & & 19 & Spread to the whole body. \\
\hline & 16 & 48 & The seizures ended at the same time. \\
\hline & 25 & 0 & Nicotinization was given to the left anterior ectosylvian gyrus. \\
\hline & & 8 & Respiration was accelerated. \\
\hline & 26 & 50 & $\begin{array}{l}\text { The seizure began in the right face and rapidly spread to the } \\
\text { left face. }\end{array}$ \\
\hline & 27 & 36 & It spread to the whole body. \\
\hline & 28 & 35 & The seizure of four limbs were stopped. \\
\hline & 30 & 45 & $\begin{array}{l}\text { The seizures of the face were stopped in both sides at the } \\
\text { same time. }\end{array}$ \\
\hline
\end{tabular}

* Salivation was also observed, but it will be neglected until a later discussion about table 15 .

2. Homolateral facial seizures following stimulation of the cortex were produced via a certain reverberating pathway

When the face area was stimulated after removing the contralateral hemisphere, clonic seizures were produced in the trunk, limbs and contralateral face muscles; they were not produced in the homolateral face. This must mean that the impulses for clonic convulsion irradiate to the homolateral face muscles via the contralateral hemisphere, and the pathway did not go through the corpus

TABLE 6. Seizures of the Contralateral Face Muscles Following Stimulation of the Face Area Could Not Be Produced after Extirpation of the Homolateral Thalamus

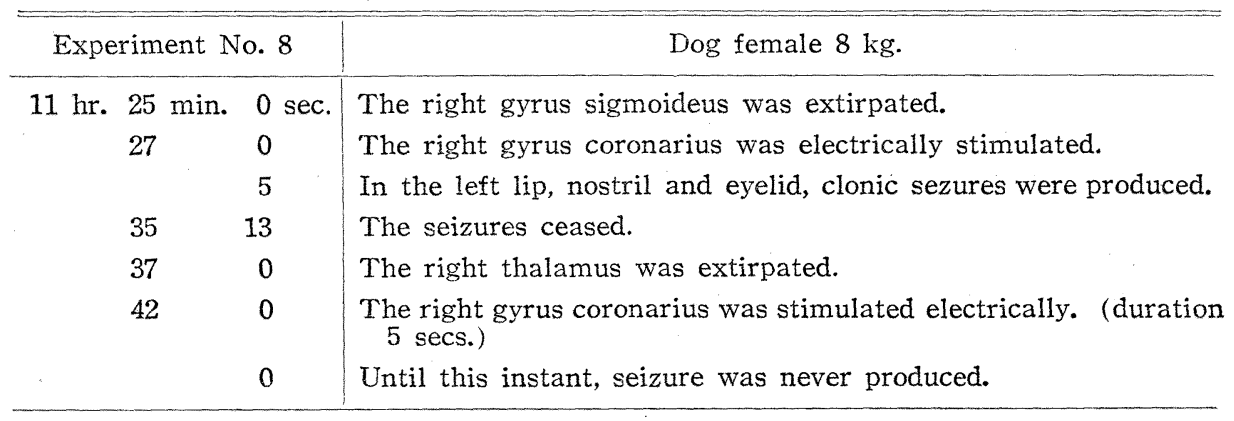


TABLE 6. (Continued)

\begin{tabular}{|c|c|c|}
\hline \multicolumn{2}{|c|}{ Experiment No. 9} & Dog male $9 \mathrm{~kg}$. \\
\hline \multirow{9}{*}{$10 \mathrm{hr} .23 \mathrm{~min}$} & 0 sec. & The left gyrus sigmoideus was extirpated. \\
\hline & 0 & $\begin{array}{l}\text { The left gyrus coronarius was electrically stimulated. (duration } \\
5 \text { secs.) }\end{array}$ \\
\hline & 8 & $\begin{array}{l}\text { In the right lip, nostril, and other face muscles the seizures } \\
\text { were produced. }\end{array}$ \\
\hline & 15 & It spread to the right eyelid. \\
\hline & 20 & The seizures above ceased at the same time. \\
\hline & 0 & The right thalamus was extirpated. \\
\hline & 0 & $\begin{array}{l}\text { The left gyrus coronarius was electrically stimulated. (duration } \\
5 \text { secs.) }\end{array}$ \\
\hline & 4 & In the right lip, nostril, eyelid and ear, the seizures were produced. \\
\hline & 45 & All stopped at the same time. \\
\hline
\end{tabular}

callosum, as shown in table 3-(7). After the contralateral face area was extirpated, stimulation of the homolateral face area showed the same results, as seen in table $3-(8)$. Therefore the indispensable part in producing the homolateral facial seizures must be the face area in the contralateral hemisphere.

Now then, what is the pathway from the face area to the contralateral face area? After extirpation of the homolateral thalamus as well as the contralateral thalamus, stimulation of the face area could not produce the homolateral facial seizures as shown in table 6 . The results mean that the clonic convulsion pathway, from the face area travel to the homolateral thalamic nuclei, which connect to the contralateral same named nuclei, and from the latter the special reverberating pathway goes to the contralateral face area.

\section{The efferent pathway of contralateral facial seizures from the cortex}

What course does the efferent pathway for clonic convulsions of the face muscles take from the cortical face area?

We have already seen that division between the longitudinal fissure down to the lower limit of the thalamus, abolished the homolateral facial seizures following stimulation of the face area, but it did not involve the contralateral facial one (See table 4). This means that the reverberating course from the face area to the contralateral face area of the cortex does pass within the thalamus, but the course to the contralateral face muscles does not cross at least above or within the thalamus. Then the problem is: does the above mentioned path have a relay in the cells of the thalamus?

It has already been reported that chemical stimulation applied to the inner part of the thalamus produced generalized epileptic seizures (2), therefore the author investigated to see if there was any part of the thalamus which through nicotinization produced facial seizures selectively. He tried to stimulate chemically several parts of the thalamus through the opened lateral ventricle in dogs, and got the results shown in table 7 . It was confirmed that the questionable pathway had a relay station in the thalamus, and it was not same, nor did it have any connection to the relay nucleus of seizures for the limbs and trunk, 
TABLE 7. Nicotinization to the Inner Cells of Thalamus Produced the Contralateral Facial Seizures

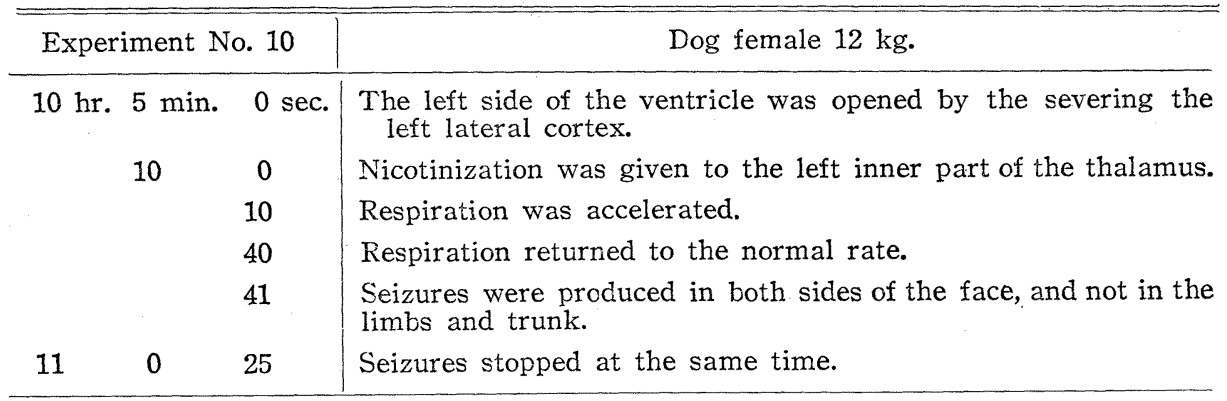

but, it had connection to the contralateral thalamus. Of course if the contralateral thalamus was extirpated, then seizures were produced in the contralateral face muscles only. (See table 6.) These results mean that the questionable path comes to the inner nucleus of the homolateral thalamus, and cross under its level.

Now, if another relay is in the midbrain, the question is whether its innervation be homolateral or contralateral from the midbrain. The experimental results were shown in table 8 . The cells that produce homolateral facials eizures were

TABLE 8. Epileptic Seizures Were Produced Selectively in the Homolateral Face by Chemical Stimulation to the Midbrain

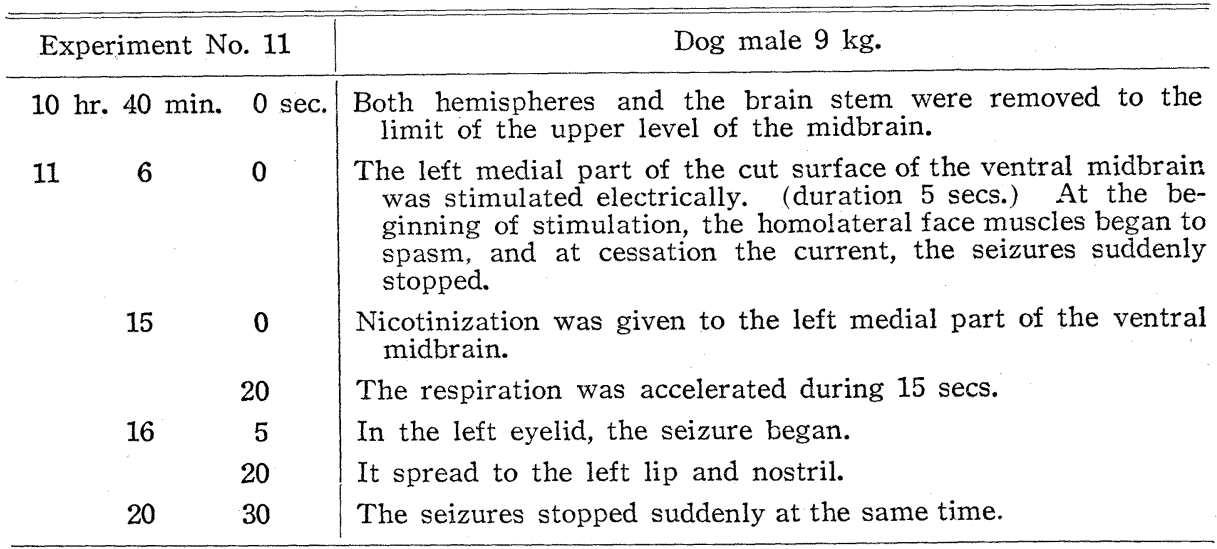

situated in the medial part of the substantia nigra, and they had no connection with the cells that produce limb seizures, which would be situated more lateral to the substantia nigra. The next relay neurones for the contralateral facial seizure crossed at a higher level than the midbrain, as will be shown in table 9 .

It was reported that the pathway of limb seizure had a relay at the thalamus and one more relay at the corpus striatum, so that the questionable path could be relayed at the globus pallidus. The author confirmed the belief that chemical stimulation to the nucleus lenticularis may produce seizure, and after elimination 
TABLE 9. The Second Relay Neurone from the Thalamus to the Midbrain Crossed at a Level under the Thalamus and over the Midbrain

\begin{tabular}{|c|c|c|c|}
\hline \multicolumn{3}{|c|}{ Experiment No. 12} & Dog male $14.5 \mathrm{~kg}$. \\
\hline $10 \mathrm{hr}$. & 25 min. & 0 sec. & The left gyrus sigmoideus was extirpated. \\
\hline & 33 & 0 & $\begin{array}{l}\text { The left gyrus coronarius was stimulated electrically. (duration } \\
10 \text { secs.) }\end{array}$ \\
\hline & & 7 & In the right nostril, eyelid and lip, epileptic seizures were produced. \\
\hline & 34 & 21 & The seizures ceased. \\
\hline & 50 & 0 & $\begin{array}{l}\text { The middle longitudinal line was cut in order to divide both } \\
\text { hemispheres and the brain stem into two parts of right and } \\
\text { left from the level of the thalamus down to the level of the } \\
\text { middle part of the midbrain. }\end{array}$ \\
\hline & 51 & 0 & $\begin{array}{l}\text { After the above operation, the left gyrus cornarius was stimulated } \\
\text { electrically. (duration } 10 \text { secs.) }\end{array}$ \\
\hline & 56 & 0 & $\begin{array}{l}\text { Observation continued during a } 5 \text { minute period, no seizures were } \\
\text { elicited. }\end{array}$ \\
\hline & 57 & 0 & The left gyrus coronarius was nicotinized. \\
\hline & 58 & 3 & Respiration was accelerated for 30 secs. \\
\hline 11 & 7 & 0 & Observation was continued for 10 minutes, no seizure was observed. \\
\hline
\end{tabular}

of it, stimulation to the face area could not produce facial seizures. The results are shown in table 10 and 11.

Seizures of the eyelids and ears were accompanied also by those of the face muscles in the case of stimulation of the globus pallidus, after extirpation of the globus pallidus, no seizures of the face or limbs were produced as shown in table 11. One might conclude that the path for all cortical seizures had a relay station in the globus pallidus. A pathway of convulsion from the cortex to the contralateral face muscles, is shown in fig. 4.

The ganglion cells situated in the cerebral cortex, projected their fibres to the thalamus and from there to the homolateral globus pallidus, from there they went to the contralateral nucleus of midbrain, from which the last neurone went

TABLE 10. Nicotinization into the Globus pallidus Produced Facial Seizures

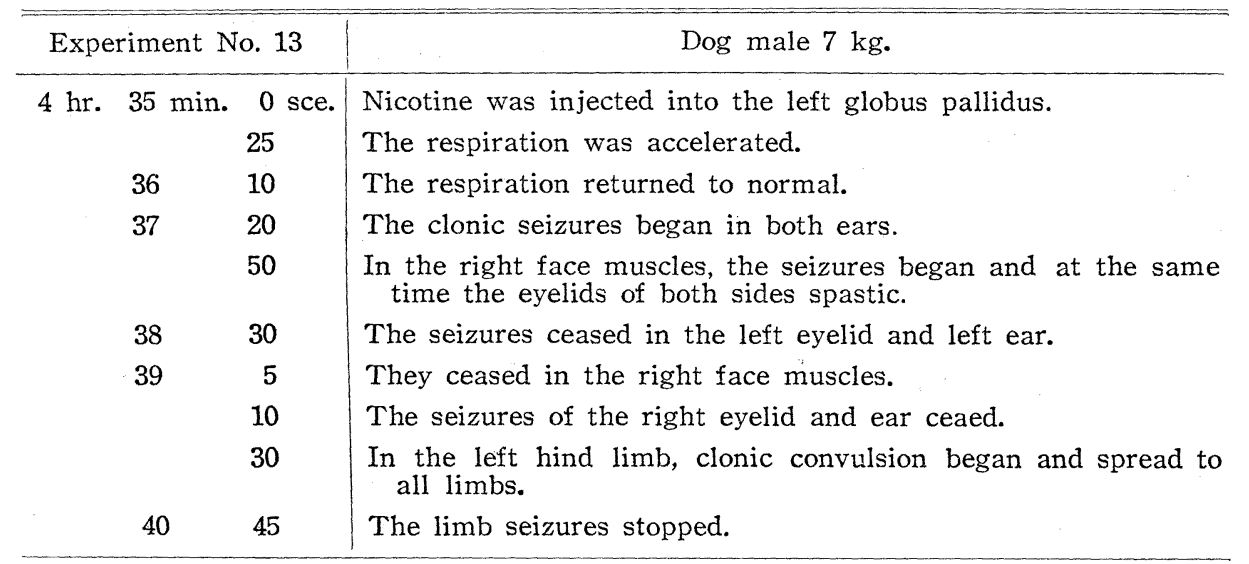


TABLE 11. After the Removal of Both Globus Pallida, Stimulation to the Cerebral Cortex Could Not Produce Any Clonic Seizure

\begin{tabular}{|c|c|c|c|}
\hline \multicolumn{3}{|c|}{ Experiment No. 14} & Dog female $10 \mathrm{~kg}$. \\
\hline $1 \mathrm{hr}$. & $0 \mathrm{~min}$. & 0 sec. & $\begin{array}{l}\text { The left gyrus sigmoideus was stimulated electrically in coil } \\
\text { distance } 160 \mathrm{~mm} \text {. (duration } 1.0 \mathrm{sec} \text {.) Tonic contractions ap- } \\
\text { peared in the extremities during stimulation, and the clonic } \\
\text { convulsion in the limbs and face did not appear. }\end{array}$ \\
\hline \multirow{2}{*}{\multicolumn{2}{|c|}{2}} & 0 & $\begin{array}{l}\text { The left gyrus sigmoideus was stimulated electrically in coil } \\
\text { distance } 120 \mathrm{~mm} \text {. (duration } 5 \text { secs.) }\end{array}$ \\
\hline & & 3 & $\begin{array}{l}\text { The clonic convulsion began in limbs and at once spread to the } \\
\text { face. }\end{array}$ \\
\hline & 30 & 0 & Globus pallidus of both sides were removed. \\
\hline & & 5 & $\begin{array}{l}\text { The left gyrus sigmoideus was stimulated electrically. (duration } \\
1 \text { sec.) The tonic convulsion in extremities was produced } \\
\text { during the stimulation in coil distance } 160 \mathrm{~mm} \text {. }\end{array}$ \\
\hline & & 10 & $\begin{array}{l}\text { The left gyrus sigmoideus was stimulated in coil distance } 120 \\
\text { mm. (duration } 5 \text { secs.) A tonic convulsion appeared during } \\
\text { the stimulation, but no clonic convulsion. }\end{array}$ \\
\hline & & 30 & $\begin{array}{l}\text { The left gyrus coronarius ant. was electrically stimulated in } \\
\text { coil distance } 120 \mathrm{~mm} \text {. (duration } 5 \text { secs.) A tonic convulsion } \\
\text { appeared in the face muscle and there was contralateral de- } \\
\text { viation of the eyes during stimulation, but no clonic convulsion } \\
\text { in the face nor in the limbs. }\end{array}$ \\
\hline
\end{tabular}

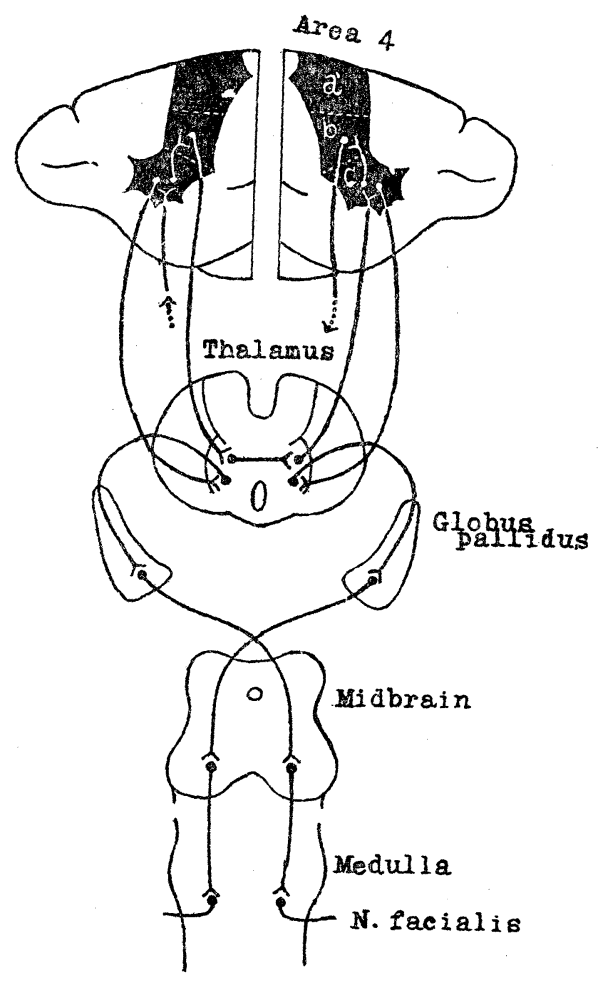

to the face muscles. The path to the eyelids and ears had a somewhat different course, about which we will have several discussions.

\section{DISCUSSION}

There are two efferent pathways of epileptic seizures for the limbs and trunk, one of which starts in the cortex and goes to the homolateral globus pallidus where there is at least one relay station, and from there it goes to the executing center in the substantia nigra and the adjacent substantia reticularis which is connected to the contralateral same named grey matter. The other path starts in

FIG. 4. The efferent pathway of the epileptic seizures for the face muscles following stimulation of cerebral cortex. 
the cortex and goes to a certain nucleus of the thalamus, the first relay station, which has a connection to the contralateral same named nucleus, from which starts the second neurone to the homolateral globus pallidus, the second relay station. The above two pathways from the globus pallidus go down the same course to the midbrain as shown in fig. 1 . When stimulation is applied to the limb area of the cortex the motor cells of the above pathways produce epileptic seizures for the limbs and trunk which will spread to the contralateral side within the thalamus and also within the midbrain.

The radiation impulses from the limb area to the face area, and vice versa, would occur in the same hemisphere but the pathway of seizures for the face is quite different from the above ones. They started in the face area and went to the thalamus, the first relay station, from which they were further conducted to the homolateral globus pallidus, the second relay station, there the third neurone started and it crossed down to the executing center of the midbrain. It was situated in the medial part of the substantia nigra, from which the path was connected down to the bulbar nuclei for the nerve of the contralateral face muscles as shown in fig. 4. The pathway seemed to have no bilateral connection in any station, however it had a special reverberating connection via the thalamus between the two hemispheres.

A so-called function of reverberation was first described by Dusser de Barrenne (1). It means that a part of the cortex is connected to another part functionally not through the association fibres within it, but through the subcortical relays. Since his work, the concept of reverberation has been applied more widely but a reverberating connection between the hemispheres and not through the corpus callosum was first noticed as above by the author.

The efferent pathways of the epileptic seizures for limbs and trunk belongs to the extrapyramidal system, for it can be produced in dogs in which the medullary pyramids had been severed experimentally, and it has several relay stations in its course to the spinal cord. The case is quite the same as that of the efferent pathway of face seizures for it is not a long path directly to the bulbar motor nuclei for face muscles and there are several relays to the motoneurones.

Seizures of the eyes and ears in monkeys did not occur through stimulation of the face area $(4 c)$. It was quite in accord with the fact that representation of the eye and ear was established outside of the motor area. Of course, in monkeys, stimulation of the cortical eye or ear field would not produce epileptic seizures in the face or limbs as shown in table 1. But it was confirmed by the author that seizures of the eyelids and ears did appear through stimulation of the frontal eye field, almost always bilaterally, as shown in table 12 .

A frontal ear field, has not been described for stimulation of any frontal area did not produce movement of the ear when the stimulation was shorter and weaker, but as shown in table 12 , it did produce a fluttering ear movements when stimulation to Areas 8 and 9 was longer and stronger. Therefore, there must be a representation of the ear in areas 8 and $9 c$, and it must be called the frontal ear field, as well as areas 22 and $7 b$, must be called the occipital ear field. The experiments showed that convulsive discharges could not irradiate from the frontal eye and ear field to area $4 c$, but they did come from area $4 c$ to the 
TABLE 12. The Representations for Eyes, Eyelids and Ears in Monkeys Were Situated Apart from Area $4 c$ (See also Table 1.)

\begin{tabular}{|c|c|c|c|c|}
\hline \multicolumn{2}{|c|}{$\begin{array}{c}\text { Area } \\
\text { stimulated }\end{array}$} & $\begin{array}{l}\text { Movement first } \\
\text { produced }\end{array}$ & $\begin{array}{c}\text { Clonic seizures in eyelids } \\
\text { and ears }\end{array}$ & $\begin{array}{l}\text { Clonic seizures in face } \\
\text { and limbs }\end{array}$ \\
\hline Area & 22 & contralateral ear & seizures of bilateral ears & - \\
\hline$" \prime$ & $7 b$ & contralateral ear & seizures of bilateral ears & - \\
\hline$" \prime$ & $19 \alpha$ & $\begin{array}{l}\text { conjugated deviation } \\
\text { of eyes to the op- } \\
\text { posite side }\end{array}$ & seizures of bilateral ears & - \\
\hline$\prime \prime$ & $8 \alpha$ & deviation of eyes & $\begin{array}{l}\text { seizures of bilateral eye- } \\
\text { lids and ears }\end{array}$ & - \\
\hline$" \prime$ & $8 \beta$ & $\begin{array}{l}\text { deviation of eyes and } \\
\text { adversive move- } \\
\text { ments of neck }\end{array}$ & - & $-*$ \\
\hline " & $8 \gamma$ & deviation of eyes & seizures of bilateral ears & - \\
\hline$" \prime$ & $8 \delta$ & $\begin{array}{l}\text { deviation of eyes and } \\
\text { adversive move- } \\
\text { menst of neck }\end{array}$ & $\begin{array}{l}\text { seizures of bilateral eye- } \\
\text { lids }\end{array}$ & $-*$ \\
\hline$" \prime$ & $9 c$ & deviation of eyes & $\begin{array}{l}\text { seizures of bilateral eye- } \\
\text { lids and ears }\end{array}$ & - \\
\hline "l & $9 d$ & deviation of eyes & - & - \\
\hline
\end{tabular}

The nerve cells for the eyelids and ears were mingled in areas 8 and 9 , the frontal eye field, from which sometimes nystagmus was induced. * When the electric current was stronger, the neighbouring face area was stimulated and we could get generalized epileptic seigures which began with adversive movement.

frontal eye and ear field. The representation of the eyelids was situated in area 4 as well as in the frontal eye and ear field, and the former was functionally unilateral as shown in fig. 4, but the latter was bilateral, therefore in the eyelids, the seizure was almost bilateral, however it was weaker in the homolateral when the stimulation was applied to area $4 c$.

In dogs, the frontal eye field was situated in prorea (see fig. 2) and the occipital eye field was situated in the areas which included gyri sylviaticus, ectosylvius, suprasylvius, ectolateralis and entolateralis as shown in table 13. The author could not confirm any special frontal field for ear movement, only in the gyri sylviaticus, ectosylvius, suprasylvius with a high concentration of ear cells, but ectolateralis and entolateralis with a low concentration, as shown in the table.

In dogs, the clonic convulsion in the eyelids and ears was produced from the face area. It was weaker in the homolateral, but in the case of stimulation outside of the face area, it was the same bilaterally. The clonic convulsion in the eyelids and ears could be produced through two paths, one from the frontal eye and ear field, as well as the whole extramotor area for the face, but the other from the face area. The former was bilateral, and the latter was contralateral only, which appeared through the homolateral globus pallidus. (See fig. 4.) And it was also probably the globus pallidus, through which these bilateral seizures appeared, for nicotinization of the globus pallidus could produce seizures of the bilateral eyelids or ears as shown in table 10 in which of course there were relay cells to the cortical epileptic seizures for limbs, so that in the end 
TABLE 13. The Representation for Eyes, Ears and Eyelids in Dogs

\begin{tabular}{|c|c|c|c|}
\hline Gyrus stimulated & $\begin{array}{l}\text { Conjugated devi- } \\
\text { ation of eyes to } \\
\text { the opposite side }\end{array}$ & $\begin{array}{c}\text { Clonic seizures of } \\
\text { ears }\end{array}$ & $\begin{array}{c}\text { Clonic seizures of } \\
\text { eyelids }\end{array}$ \\
\hline $\begin{array}{l}\text { Gyr. sylviaticus } \\
\text { ant. } \\
\text { med. } \\
\text { post. }\end{array}$ & $\overline{-}$ & $\begin{array}{l}\text { H } \\
\text { H } \\
\text { H }\end{array}$ & $\begin{array}{l}+ \\
+ \\
+\end{array}$ \\
\hline $\begin{array}{l}\text { Gyr. ectosylvius } \\
\text { ant. } \\
\text { med. } \\
\text { post. }\end{array}$ & $\begin{array}{l}H \\
H \\
H\end{array}$ & $\begin{array}{l}\text { W } \\
\text { W } \\
\text { H }\end{array}$ & $\begin{array}{l}H \\
H \\
H\end{array}$ \\
\hline $\begin{array}{l}\text { Gyr. suprasylvius } \\
\text { ant. } \\
\text { med. } \\
\text { post. }\end{array}$ & $\begin{array}{l}\text { W } \\
\text { W } \\
\text { H }\end{array}$ & $\begin{array}{l}+ \\
+ \\
+\end{array}$ & $\begin{array}{l}H \\
H \\
H\end{array}$ \\
\hline Gyr. ectolateralis & H & + & H \\
\hline Gyr. entolateralis & H & + & \# \\
\hline Prorea & H & - & + \\
\hline
\end{tabular}

of the table, the experiment produced seizures of the limbs.

As shown in the first paper of the author (2), after total extirpation of the motor area (Area 4 in monkeys), stimulation of the extramotor area (shaded areas except Area 4 in fig. 1) could not produce the clonic convulsion at all. The author called this phenomenon the "law of final common area" for epileptic seizures. Was this law true also for the face area? Table 14 showed an experiment, in which the total extirpation of the face area stopped seizures of the face muscles, and table 15 showed that after total extirpation of the face area, clonic convulsions from the whole extramotor area could not be produced.

Now, another problem is that of the secretion of asliva which should occur

TABLE 14. The Face Area was the Final Common Area to the Whole Extramotor Cortex for the Epileptic Seizures for Face Muscles

\begin{tabular}{|c|c|c|c|}
\hline \multicolumn{3}{|c|}{ Experiment No. 15} & Dog male $12 \mathrm{~kg}$. \\
\hline \multirow[t]{8}{*}{$4 \mathrm{hr}}$. & 7 min. & $0 \mathrm{sec}$. & $\begin{array}{l}\text { The left gyrus postcruiatus was electrically stimulated. (dura- } \\
\text { tion } 10 \text { secs.) }\end{array}$ \\
\hline & & 3 & The seizures began in the four limbs. \\
\hline & & 13 & It generalized to the face of both sides. \\
\hline & & 40 & $\begin{array}{l}\text { The seizure continued, and the face area of the left hemisphere } \\
\text { was extirpated, its small part remaing. }\end{array}$ \\
\hline & 8 & 0 & $\begin{array}{l}\text { The seizure continued, along the course of the face muscles of } \\
\text { both sides. }\end{array}$ \\
\hline & & 8 & The remaining face area was totally extirpated. \\
\hline & & 10 & The seizure ceased suddenly in both sides of the face. \\
\hline & & 30 & At this moment, the seizures of the four limbs ceased. \\
\hline
\end{tabular}


TABLE 15. When Seizures of the Face Muscles Were Not Produced after the Extirpation of the Face Area, the Secretion of Saliva Did Not Appear Notwithstanding the Appearance of Seizures of Limbs and Trunk

\begin{tabular}{|c|c|c|}
\hline \multicolumn{2}{|c|}{ Experiment No. 16} & Dog female $12 \mathrm{~kg}$ \\
\hline $10 \mathrm{hr} .30 \mathrm{r}$ & 0 sec. & $\begin{array}{l}\text { The left gyrus postcruciatus was stimulated electrically (dura- } \\
\text { tion } 5 \text { secs.) }\end{array}$ \\
\hline & 3 & The clonic seizures began in the limbs. \\
\hline & 12 & $\begin{array}{l}\text { At once spread to the face, copious secretion of saliva was } \\
\text { mentioned. }\end{array}$ \\
\hline 34 & 20 & The seizures ceased at the same time in the limbs and face. \\
\hline 35 & 56 & The flow of saliva ceased. \\
\hline 37 & 0 & $\begin{array}{l}\text { The left face area and its boundary region to gyrus sigmoideus } \\
\text { was extirpated. }\end{array}$ \\
\hline \multirow[t]{2}{*}{39} & 0 & $\begin{array}{l}\text { The left gyrus postcruciatus was stimulated electrically (dura- } \\
\text { tion } 5 \text { secs.) }\end{array}$ \\
\hline & 4 & $\begin{array}{l}\text { Clonic convulsion occurred in all limbs but did not spread to } \\
\text { the face muscles. No saliva fow. }\end{array}$ \\
\hline 40 & 17 & The seizures ceased. \\
\hline 50 & 30 & $\begin{array}{l}\text { About } 10 \text { minutes after the cessation of the above seizures, no } \\
\text { saliva secretion was observed. }\end{array}$ \\
\hline
\end{tabular}

during the epileptic seizures. The author discussed previously that stimulation of the motor cortex of the higher animals produces several forms of movement of the skeletal muscle, for example, phasic, tonic, clonic and alternating, but saliva secretion accompanies the clonic movement only.

The tables already shown, in this paper focus mainly upon convulsions and salivary secretion was neglected. but in table 15 an experiment was described as an example, in which an observation of saliva was described. The table showed that salivary secretion accompanied only the clonic convulsion of the face muscles, not that of the limbs and trunk. The clinical reports published on epileptic fits by Japanese doctors have contained cases in which the patients had only the secretion of saliva and spasms of the face, but to our great regret no author gave special care to the relationship between salivary secretion and the form of convulsions. The author feels that in the future, if observation is given specially to that point in clinical cases, the physiological event on the separation of seizures of the face and limbs as well as on the secretion of saliva, from the results of the animal experiments, would be a clue of more precise observation of the symptoms of epilepsy.

\section{SUMMARY}

1. Stimulation electrically as well as chemically applied to the motor face area of the cortex produced generalized epileptic seizures in the limbs and face muscles in monkeys as well as in dogs.

2. After removing the homolateral leg and arm area, stimulation to the face area produced epileptic seizures only in the contralateral face muscles in monkeys as well as in dogs. 
3. After the face area of the cortex was removed, stimulation of the limb or arm area produced seizures in all limbs and trunk and in the ipsilateral face muscles in monkeys as well as in dogs.

4. Seizures of the homolateral face muscles following stimulation of the face area could not be produced when the contralateral hemisphere, especially, its face area was removed, and also when the homolateral or the contralateral thalamus was removed in dogs.

5. Epileptic seizures for the face muscles as well as for limb muscles following cortical stimulation could not appear after the globus pallidus in both sides were removed, on the contrary, the tonic contraction could be produced. Chemical stimulation to the globus pallidus produced epileptic seizures of all limbs, the homolateral face muscles in dogs and of bilateral eyelids and ears.

6. Stimulation of the frontal eye field produced a conjugate deviation of the eyes to the opposite side and clonic convulsion of the eyelids and ears. It did not produce seizures of the face muscles nor limb muscles in monkeys as well as in dogs. It was established that the frontal eye field in dogs was situated in the prorea (in front of the gyrus compositus ant.).

7. The efferent pathway of the epileptic seizures for face muscles differed from that for limb muscles. It took the course that the cells of the cortical area for face projected to the homolateral thalamus from which the second neurone to the homolateral globus pallidus. The third neurone started in the globus pallidus, crossed at the level between the thalamus and midbrain and reached the medial side of the substantia nigra and its posterior locus of substantia reticularis, which would be the executing center of an epileptic spasm of the muscles of that half of the face from which the fourth neurone got to the nuclei of the cranial nerves for face muscles.

8. The copious secretion of saliva which accompanied the epileptic seizure could not be produced when seizure of the face could not be elicited in monkeys as well as in dogs.

\section{REFERENCES}

1. Dusser de Barrenne J. G. AND MCCulloch W. S. Functional organization in the sensory cortex of the Monkey (Macacca mulatta). J. Neurophysiol. 1: 59-85, 1938.

2. HAYASHI T. A physiological study of epileptic seizures following cortical stimulation in animals and its application to human clinics. Jap. J. Physiol. 3: 47-64, 1952.

3. HAYASHI T. Cortical mastication and its efferent pathway in dogs. Keio J. Medicine. 1: 175-187, 1952.

4. VoGT O. AND VOGT C. Ergebrnisse unserer Hirnforschung. J. Psychol. Neurol. 25: 277462, 1919. 